\title{
NBSIR 75.640 \\ Metallurgical Analysis of Wear Particles and Wearing Surfaces
}

A. W. Ruff

Metallurgy Division

Institute for Materials Research

National Bureau of Standards

Washington, D. C. 20234

January 1,1975

Interim Report for Period October 1 through December 31, 1974

Contract 4-8049

Prepared for

Department of the Navy

Naval Air Engineering Center

Philadelphia, Pa. 19112 
NBSIR $75-640$

\section{METALLURGICAL ANALYSIS OF WEAR \\ PARTICLES AND WEARING SURFACES}

\section{A. W. Ruff}

Metallurgy Division

Institute for Materials Research

National Bureau of Standards

Washington, D. C. 20234

January 1,1975

Interim Report for Period October 1 through December 31, 1974

Contract 4-8049

Prepared for

Department of the Navy

Naval Air Engineering Center

Philadelphia, Pa. 19112

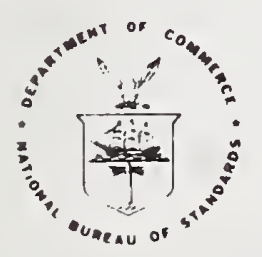

U. S. DEPARTMENT OF COMMERCE, Frederick B. Dent, Secretary 

The objective of the project has been to characterize the wear particles and surface degradation produced by wear in bearing and gear tests in which the effect of several variables on failure of the wearing surfaces has been examined. The information obtained has been correlated with the results of allied studies conducted by others in an attempt to develop an understanding of the processes producing wear and degradation of metal surfaces in sliding, rubbing, rolling, and/or rotating contact and the effects of lubricants, lubricant additives, bearing materials, etc. on these processes. The characterization of the wear particles and wearing surfaces should aid in the establishment of the interrelationships between wear particle shape, size, size distribution, chemical compositions, metallurgical structure, and surface damage prior to failure.

\section{APPROACH}

The initial approach has been concerned primarily with the examination of particles recovered by the Ferrographic technique from samples of lubricating oils taken periodically during tests and service of bearings, gears, sliding surfaces, etc., in which such experimental variables as lubricants, lubricant additives, bearing materials, loads, etc., have been studied. Our examinations have been conducted principally using both Scanning and Transmission Electron Microscopy techniques, observing particle shapes, sizes, surface structures and other parameters as functions of distance along the Ferrogram and determining a semiquantitative elemental chemical analys is of selected and typical particles. These electron microscope techniques have been used to characterize the wear particles and associated surface degradation produced in the bearing and gear tests conducted by others. They provide information on particles and surface details too small for study by optical microscopy methods.

After suitable techniques have been developed for examining and characterizing both the wear particles and the surfaces that produced them, these methods will be used to examine and evaluate specimens removed or obtained from programmed wear tests being conducted on associated projects. 


\section{RESULTS AND DISCUSSION}

\section{A. Wear Debris Analysis}

1. Diesel Engine 0il Sample (F-3319)

An unusual wear debris specimen was examined in detail following preparation and study by Trans-Sonics. The specimen was obtained from a diesel engine and was found to contain relatively large, bright yellow particles in addition to the usual iron wear particles. Other mineral-appearing particles were also noticed in the Ferrograms that were prepared. Figure 1 shows an area from one Ferrogram containing several large yellow colored particles as viewed in white, reflected light. The Ferrogram was coated with a thin layer of deposited carbon in a vacuum evaporator as previously described and then examined in the scanning electron microscope. Figure 2 shows the entry deposit region (oil flow is downward). Figure 3 provides detail in the region indicated in Fig. 2. Particle $\underline{A}$ is the original particle of interest. $X$-ray microanalysis was conducted on particle $\underline{A}$ and several other particles on the Ferrogram. The spectrum from particle $\underline{A}$ is shown in Fig. 4 to consist of principally sulfur and chromium. The small silicon contribution probably originates from the glass slide substrate. Particle $\underline{C}$ (actually several small particles) is the usual iron wear fragment found in particle strings on the Ferrogram as confirmed by the spectrum shown in Fig. 5. Relative analyses of all particles labeled in Fig. 3 are as follows:

$$
\begin{aligned}
\text { Particle } A: & 3 S+1 \mathrm{Cr} \\
C: & \mathrm{Fe}+\text { trace } S \\
D: & 1 S+3 \mathrm{Ca} \\
F: & 1 S+2 \mathrm{Ca}+3 \mathrm{Fe} \\
G: & 1 S+1 \mathrm{Ca} \\
H: & 1 S+1 \mathrm{~K}+3 \mathrm{Ca}
\end{aligned}
$$

Sulfur was found as a principal constituent of most of the larger particles analyzed. It probably was introduced into the system through the use of sulfur-containing diesel fuel and oils. Spectrometric analysis of this oil indicated the following elemental content in parts per million: $\mathrm{B}=1.2, \mathrm{Si}=88, \mathrm{Ag}=5.8, \mathrm{Fe}=8.1, \mathrm{Cr}=23, \mathrm{Cu}=13$, 
$\mathrm{Pb}=9.7, \mathrm{Sn}_{\mathrm{n}}=5.0, \mathrm{Al}=23, \mathrm{Zn}=42, \mathrm{Ca}=248$. An unusually high

Ca content was found in several of the individual particles analyzed.

Figure 6 shows another area near the initial deposit point, also marked in Fig. 2. The larger particles in this area also were found to contain a significant amount of sulfur. In view of the location of these sulfur-containing particles, at the end of or imbedded within magnetic particle strings, it is clear that these sulfur-containing particles contain a significant amount of iron or smaller iron wear particles. It is not clear whether actual sulfur-iron compounds are involved here or whether a physical aggregation process occurs. In view of the possible increased use of higher sulfur-containing fuels and lubricants in our technology, the influence of sulfur in wear debris analysis (if any) needs examination.

\section{ONR Lubricating 0 il Sample (F-3356)}

This specimen was provided through Trans-Sonics after an inquiry into what information might be deduced from a wear debris particle examination. The actual mechanical system involved was not revealed. The results are presented here as unusual and illustrative. Figure 7 is a reflected, white light photomicrograph of one region of the Ferrogram after heating to $330^{\circ} \mathrm{C}$. That treatment caused a blue coloration of the iron and stee 1 debris and is one principal analytical step taken in the examination of many Ferrograms from mixed-metal systems. Note that the particle labeled $\underline{A}$ (and several others) have a distinctively different color.

The Ferrogram was carbon-coated by vacuum deposition and examined in the SEM. Figure 8 shows the area near the entry deposit containing particle A. Several unusually large flake particles are seen, as are numerous larger, equi-axed particles, all generally oriented with the iron wear particle strings. X-ray microanalys is indicated that particle $\underline{A}$ was composed of chromium, probably originating in a $\mathrm{Cr}$-plated portion of the mechanical system. Figure 9 shows the emission spectrum for $\underline{A}$. Particle $\underline{B}$ gave a very similar, $\mathrm{Cr}$-rich spectrum. Particle $\underline{C}$ and others of similar appearance were rich in calcium and gave evidence of containing significant oil residue. The region of the particle 
string to the right of particle $\mathrm{C}$ in Fig. 8 is shown in Fig. 10. Several small flake particles are seen here along with two $4 \mu \mathrm{m}$ diameter spheroids. Analysis of the spheroids indicated only an iron content. Many other spheroids were observed in this Ferrogram. Further down from the initial deposit, a nonmagnetic copper particle was found and is shown as $\underline{D}$ in Fig. 11. Note that the smaller iron particles still deposit in a laterally oriented string-like configuration, quite distinct from the larger particles nearby. That difference suggests the nonferromagnetic composition as verified in the case of particle $\underline{D}$.

\section{B. Ferrograph Evaluation}

Studies have continued into the behavior of the $5 \mu \mathrm{m}$ diameter nickelimpregnated, porous silica spheres as ferromagnetic particles in oil. Samples of these particles are passed through the Ferrograph in order to evaluate the instrument characteristics. An experiment currently in progress involves a mixture of nickel-coated and uncoated $5 \mu \mathrm{m}$ spheres. The uncoated spheres should pass through the Ferrograph while the nickel-coated spheres are magnetically trapped on the substrate. Figure 12 shows the entire deposit region ( F-3420) at low magnification in an optical microscope. A gradual decrease in deposit density in the direction of the oil flow is seen. The initial deposit is very dense. The number of spheres in the strings appears to decrease steadily toward the bottom of the Ferrogram. Measurements of the nickel content of the spheres along the slide are in progress to see whether those spheres that reach the bottom of the slide systematically have lower $\mathrm{Ni}$ content (note that the sphere size is reasonably constant at $5 \pm 1 \mu \mathrm{m})$. Ideally all spheres of the same size and $\mathrm{Ni}$ content should deposit closely in the same region. Preliminary but close examination of the strings indicates relatively few uncoated $\mathrm{SiO}_{2}$ spheres. Figure 13 shows an area near the initial deposit and three transparent, uncoated spheres are seen in strings (arrows). More commonly the nonferromagnetic, uncoated spheres are found to deposit randomly on the slide as seen at A. These studies should provide useful information on the behavior of nonmetallic, abrasive particles in oil samples that subsequently undergo Ferrographic analys is and also on nomagnetic metallic particles. We 
plan next to examine the fluid that passes through the Ferrograph to determine the particles contained therein.

Another experiment has been conducted using only nickel-coated $5 \mu \mathrm{m}$ spheres. The mechanism of lateral growth of the particle strings as additional particles pass over them was of interest. Figure 14 shows a scanning electron micrograph of the entry deposit region of that Ferrogram (F-2897). Note again the gradual decrease in particle density along the flow direction. Figure 15 indicates some detail adjacent to the entry deposit. The usual process of deposit thickening appears to involve the addition of a second row of particles on the substrate adjacent to the first row. Another particle row can then deposit on top of the two lower rows, etc. Lateral lengthening and thickening appear to go on together. The unusual background contrast near the strings in this example is due to residual oil left on the Ferrogram. The carbon film deposit does not adhere in the regions of this oil and particle charging in the electron beam can occur. This problem is most serious in any ferrogram examination since the debris particles are not fixed to the substrate in such cases and can be dislodged and lost. Figure 16 illustrates this effect in this sample. Locations of several short strings of particles are shown to be empty $(A)$ and displaced, single spheres are seen at random adjacent locations.

A mixed sample of nickel-coated spheres of $5 \mu \mathrm{m}$ and $0.7 \mu \mathrm{m}$ diameter is also being studied. The emphasis here concerns the growth and characteristics of the particle strings when a bimodal size distribution of particles is present. An area near the entry deposit in F-2902 is seen in Fig. 17. The particle strings here are all rather short and unconnected due to a lower particle density and coverage. Figure 18 shows some details near two strings. The small spheres appear in clusters in and on the end of many strings; they also appear in isolated locations, usually clustered in groups of five or more. It is not expected that the 0.7 um spheres should deposit consistently in the same strings with the $5 \mu \mathrm{m}$ spheres unless they are clustered into larger effective sized units in the oil. Further experiments will examine the tendency to cluster and methods for better dispersion. 
Another string of mixed size spheres is shown in detail in Fig. 19. Some small clusters of $0.7 \mu \mathrm{m}$ spheres are seen at the ends and along this string. Clearly small submicron wear debris would behave in a similar manner relative to large particles.

\section{Particle Microanalysis}

Further studies are in progress on the reliability of $X$-ray microanalys is methods applied to particle collections in the micron size range. The particles labeled in Fig. 19 were examined under constant electron beam exposure and geometrical conditions. The $\mathrm{Ni}-\mathrm{K} \alpha \mathrm{X}$-ray line emission was measured in each case using the SEM $X$-ray detector system. The results are given below.

\begin{tabular}{l|c|c|c|c|c|c|c|c|c|c|c|c|c|c} 
Particle & 1 & 2 & 3 & 4 & 5 & 6 & 7 & 8 & 9 & $A$ & $B$ & $C$ & $1 R$ & $9 R$ \\
\hline $\begin{array}{l}\text { Time for } \\
10^{3} \text { counts } \\
\text { (sec.) }\end{array}$ & 108 & 87 & 79 & 70 & 77 & 104 & 76 & 60 & 58 & 350 & 112 & 360 & 99 & 53 \\
\hline
\end{tabular}

Particles A, B, C are actually clusters of the smaller spheres. The variation in $\mathrm{Ni}$ count rate for the $5 \mu \mathrm{m}$ spheres is due partially to statistical variations (about $6 \%$ ) and partially to a real variation in $\mathrm{Ni}$ content of the spheres. The observed average value is $80 \pm 18 \mathrm{sec}$., a variation of about $25 \%$. The string was rotated 180 degrees in the SEM and the end particles reanalyzed. The values (IR, 9R) are not significantly different than the original values, indicating that electron excitation from adjacent particles is not a significant factor. The $\mathrm{Ni}$ emission from the cluster of small spheres $\underline{B}$ is reasonably close to that from the larger spheres suggesting a similar $\mathrm{Ni}$ content. The clusters $A$ and $C$ appear thinner and penetration of the electron beam would be more significant.

A previous study of the $\mathrm{Ni}$-coated $5 \mu \mathrm{m}$ spheres, selected to be isolated from other spheres on the substrate, revealed the variation in $\mathrm{Ni}$ content shown in Fig. 20, also about 25\%. Calculations and experiments on the effect of penetration of small particles by the electron beam and subsequent $X$-ray emission have been reported last quarter. Figure 21 shows the results for iron(nickel results are nearly identical). No correction for $X$-ray emission is needed for the $5 \mathrm{um}$ spheres. However, a factor 
of about 0.3 is indicated for correction at $0.7 \mu \mathrm{m}$ diameter. Considering particle clusters $A$ and $C$ in Fig. 19, the corrected time for $10^{3}$ counts would be $(350)(0.3) \simeq 100 \mathrm{sec}$, which is reasonably consistent with the values for the $5 \mu \mathrm{m}$ spheres.

\section{Acknowledgments}

The assistance of Paul Boyer in obtaining and reporting these results is appreciated. The silica sphere samples were provided through the kind cooperation of Drs. J. P. Wolf III and R. K. Ider, E. I. DuPont, Company. 
Fig. 1. Optical reflected light photograph of diesel engine oil Ferrogram-3319.

Fig. 2. Scanning electron micrograph of entry region in F-3319.

Fig. 3. Details in F-3319, compare with Fig. 1.

Fig. 4. X-ray spectrum from particle A in Fig. 3.

Fig. 5. X-ray spectrum from particles $\underline{C}$ in Fig. 3 .

Fig. 6. Details in another area of Fig. 2.

Fig. 7. Optical reflected light photograph of F-3356 after heating to $330^{\circ} \mathrm{C}$.

Fig. 8. Scanning electron micrograph of region in Fig. 7.

Fig. 9. X-ray spectrum from particle $A$ in Fig. 8.

Fig. 10. Particle string containing two iron spheroids adjacent to area of Fig. 8.

Fig. 11. Region of F-3356 downstream from entry deposit. Particle $\underline{D}$ is principally copper.

Fig. 12. Ferrogram-3420 deposit; optical micrograph of $5 \mu \mathrm{m} \mathrm{Ni} / \mathrm{SiO}_{2}$ spheres.

Fig. 13. Optical photograph of strings near entry deposit. Note transparent spheres marked.

Fig. 14. Entry deposit of F-2897, scanning electron micrograph, collection of $5 \mu \mathrm{m} \mathrm{Ni} / \mathrm{SiO}_{2}$ spheres.

Fig. 15. Details of particle strings near entry deposit.

Fig. 16. Instability of particle strings due to oil contamination.

Fig. 17. Scanning electron micrograph near entry deposit of F-2902,

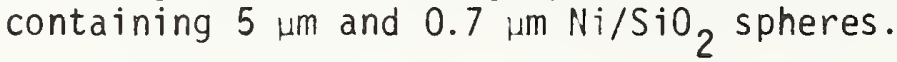

Fig. 18. Details of particle strings in F-2902.

Fig. 19. String of both sized spheres in F-2902.X-ray data obtained from marked spheres (see text).

Fig. 20. Number of $5 \mathrm{~m} \mathrm{Ni} / \mathrm{SiO}_{2}$ spheres giving rise to fixed $\mathrm{Ni}-\mathrm{K}_{\alpha}$ counts vs. count time. Indicates uniformity of nickel content in selected, isolated spheres.

Fig. 21. Experimental data and calculated curve showing effect of particle size on $X$-ray emission intensity for iron (nickel nearly identical). 


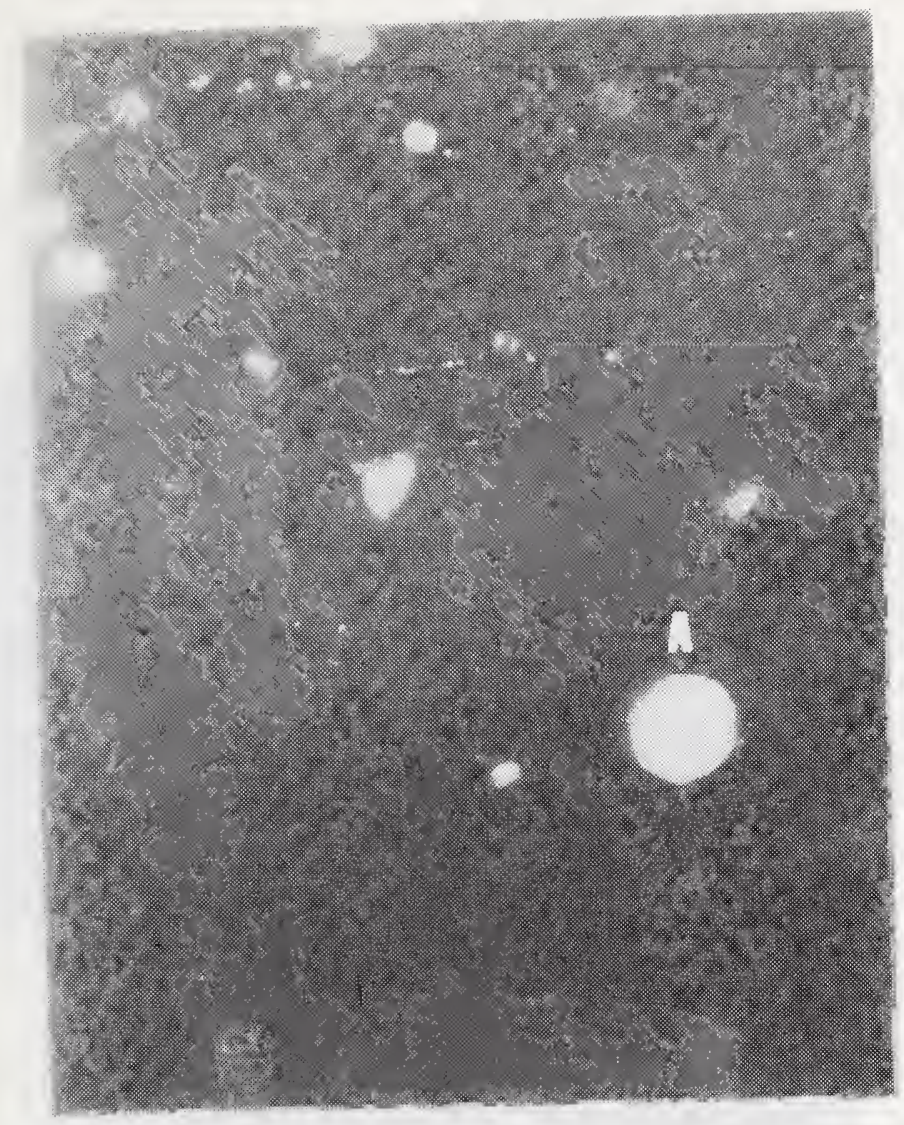

Fiqure?

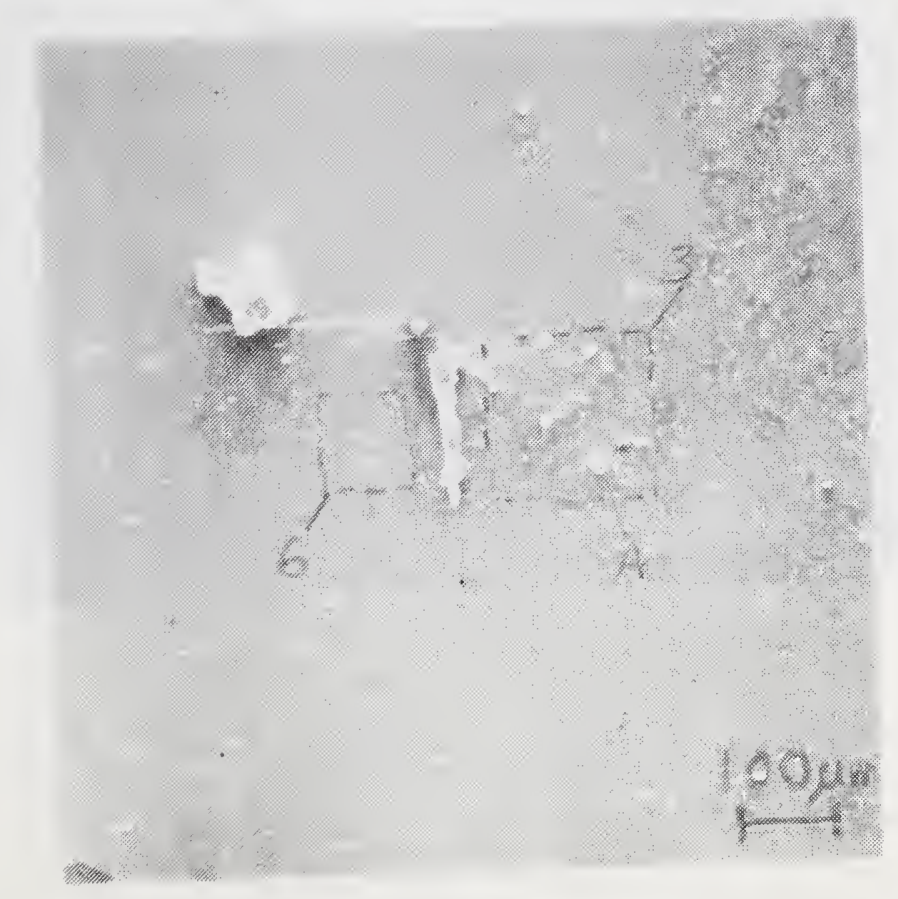

Fiqure? 


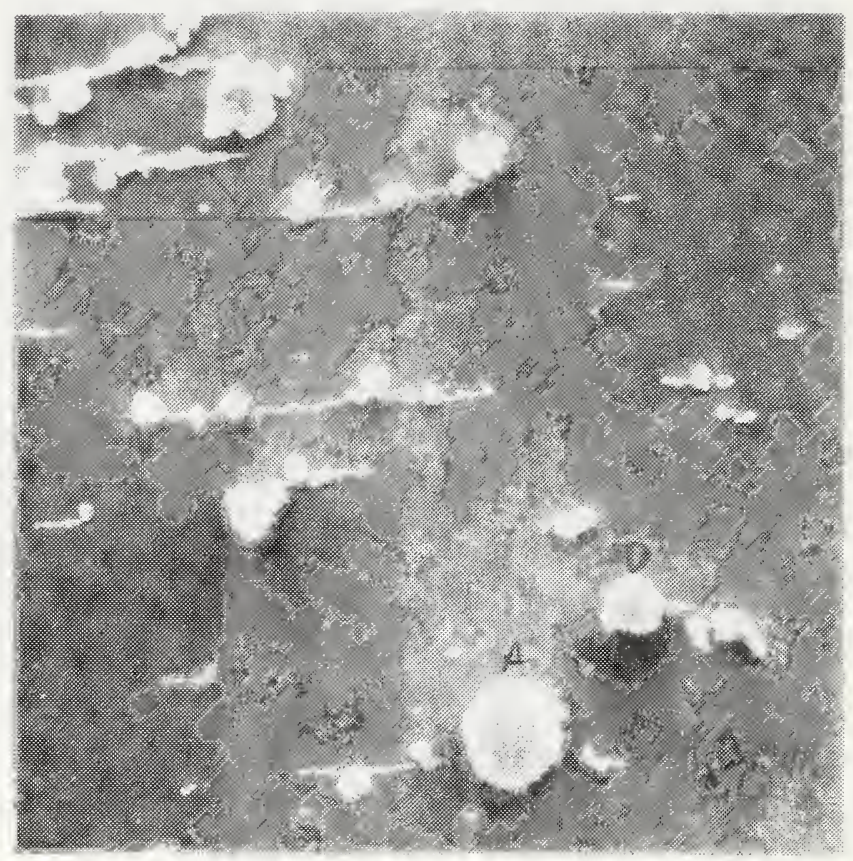

Fiqure 3

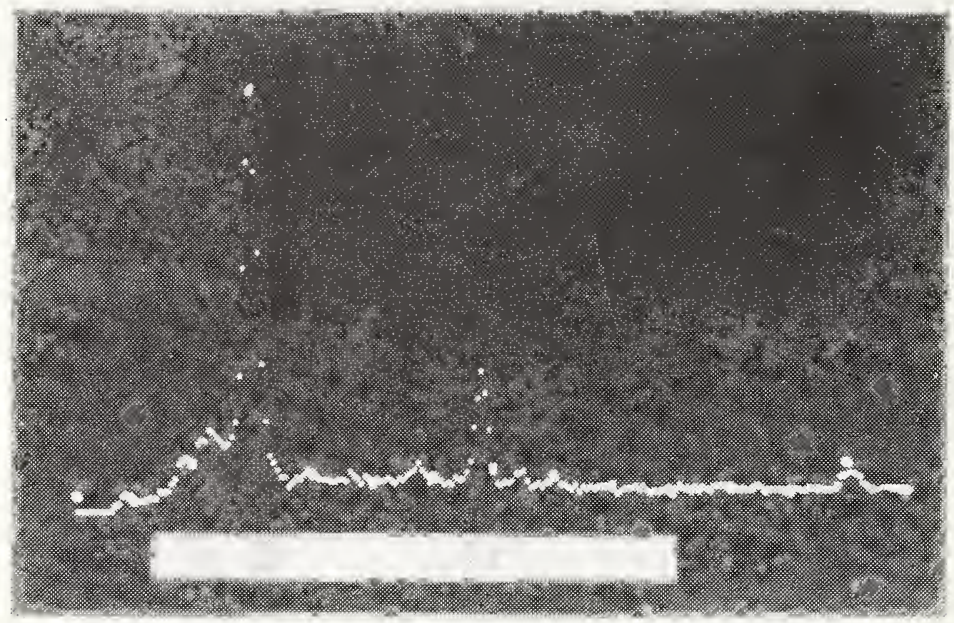

Figure 4 


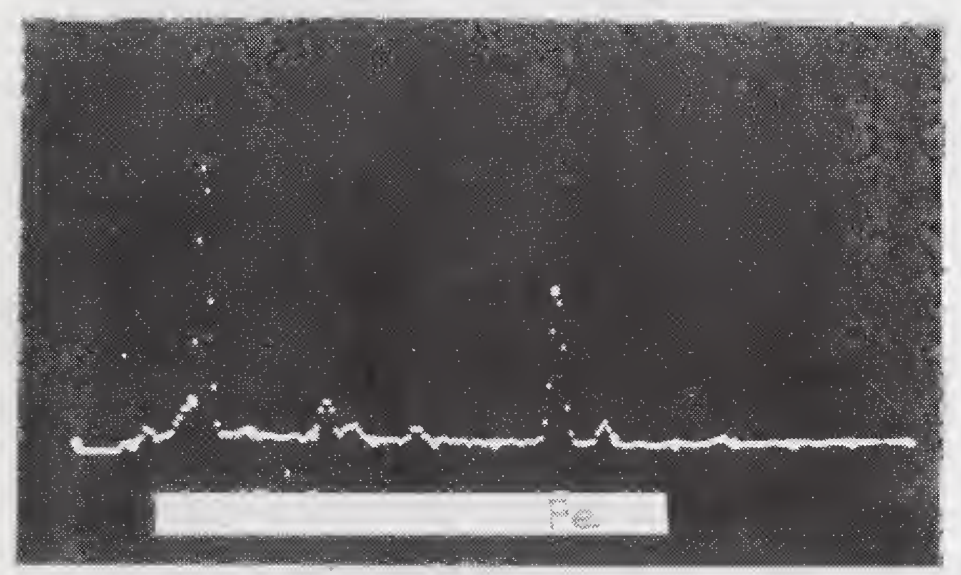

Figure 5

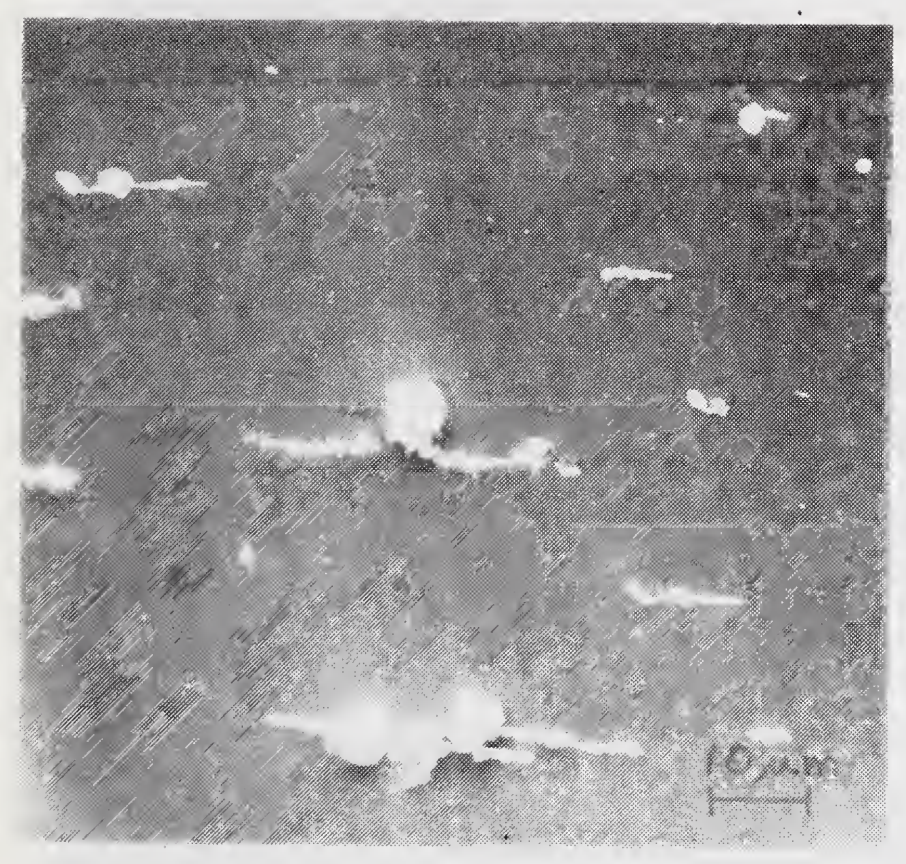

Figure 6 


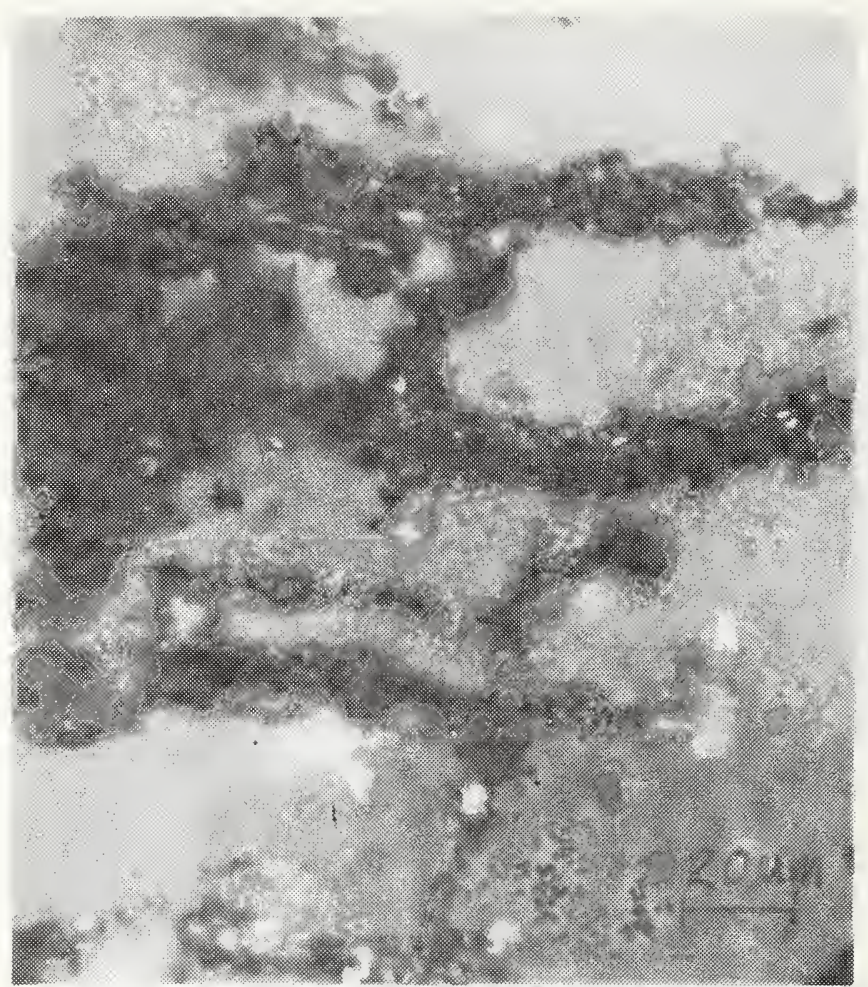

Figure 7

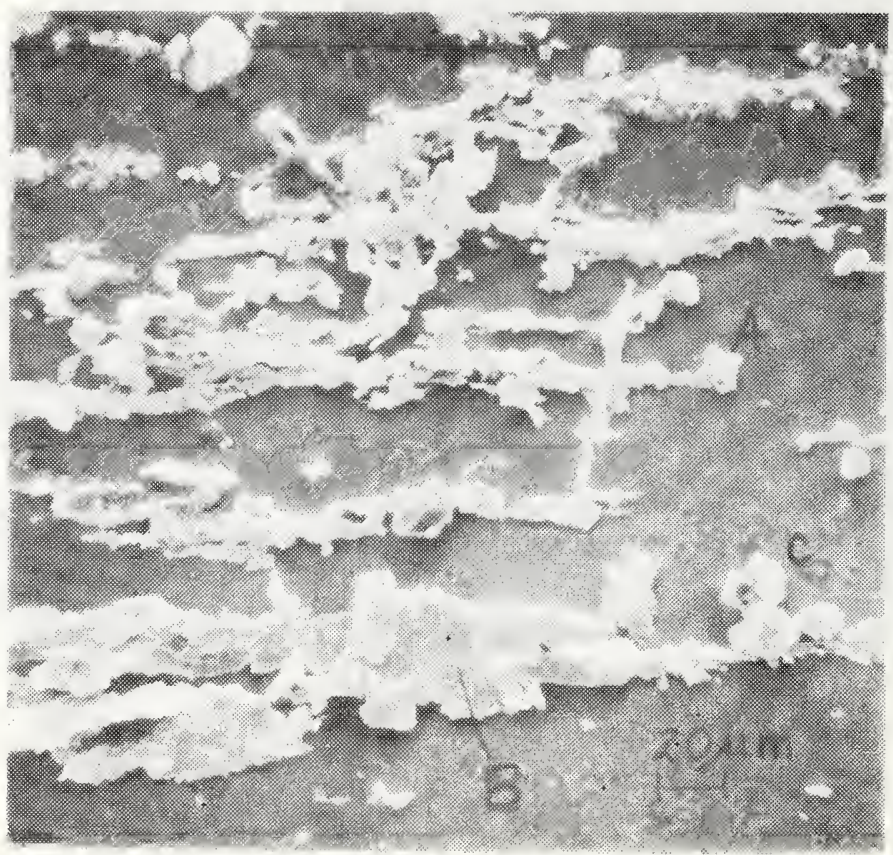

Figure 8 


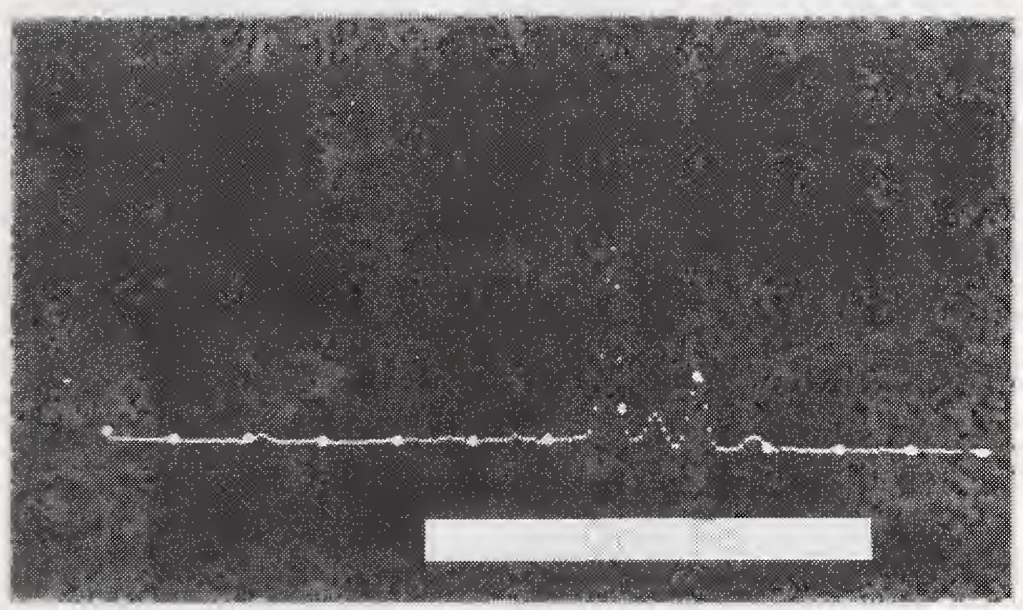

Figure 9

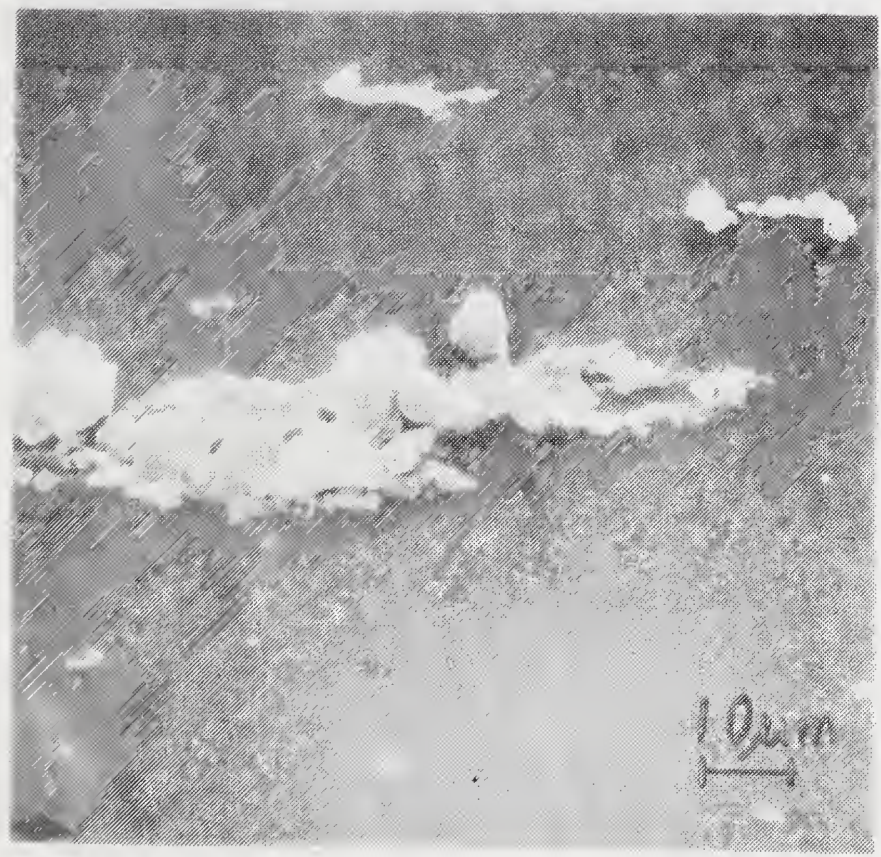

Fiqure 10 


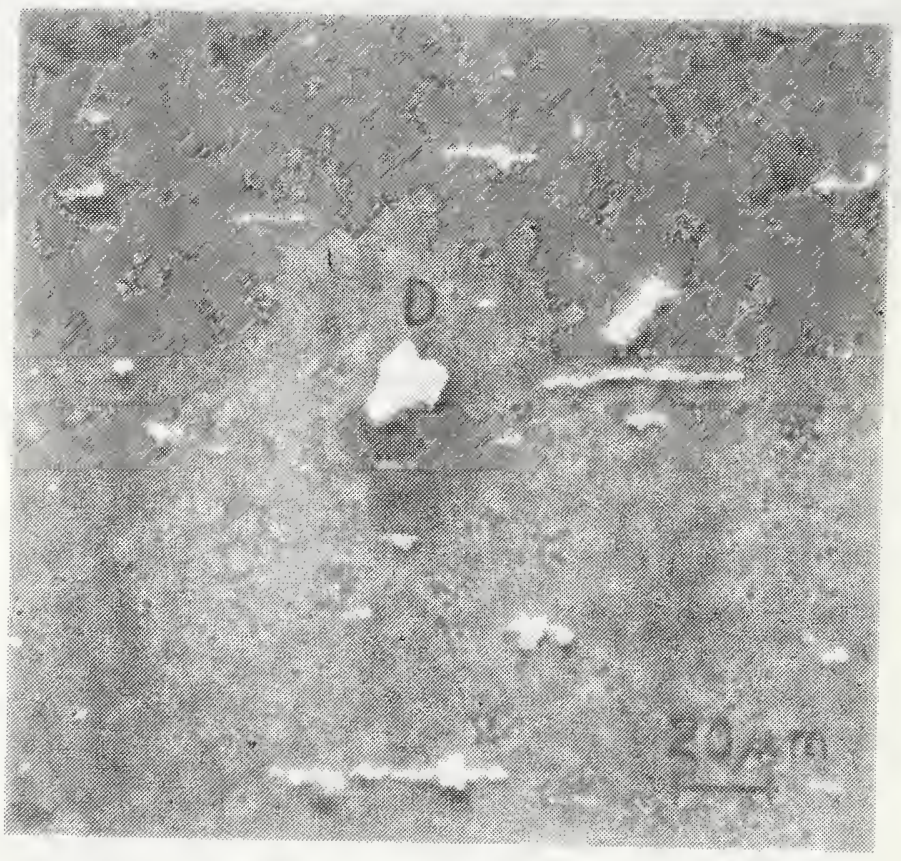

Fiqure 11 


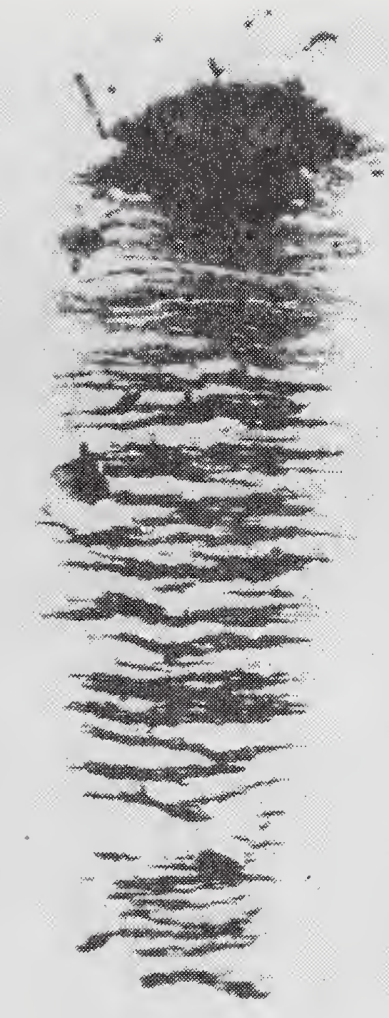

Figure 12

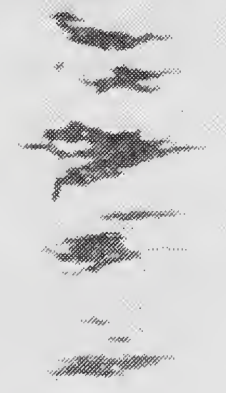

max

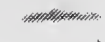




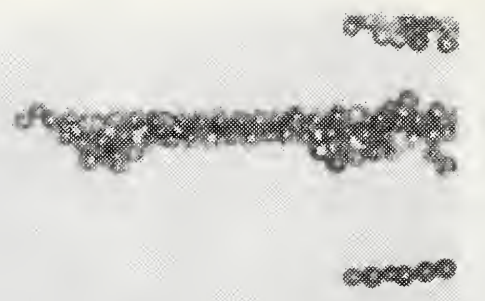

Figure 13

2.

.
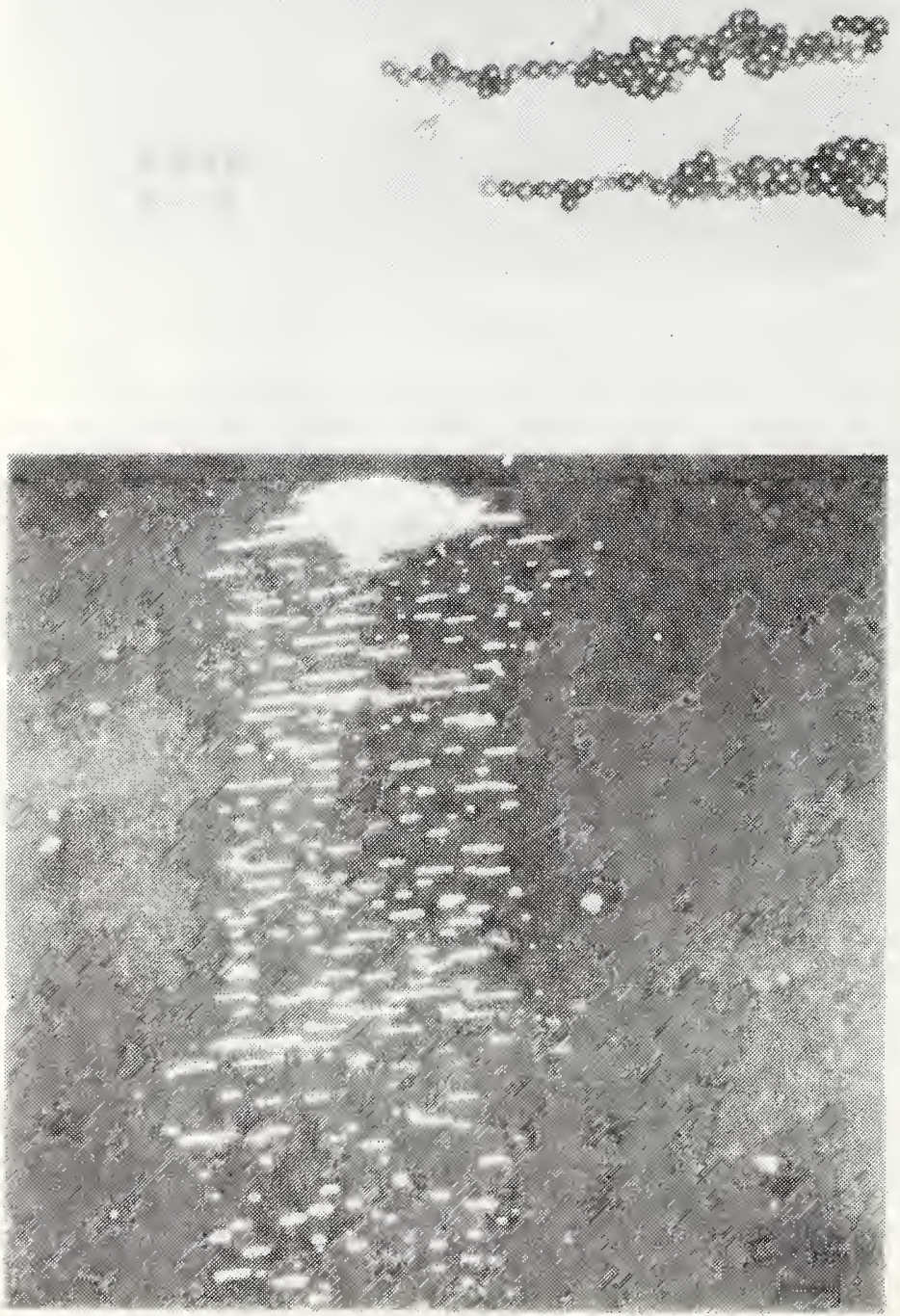

Figure 14 


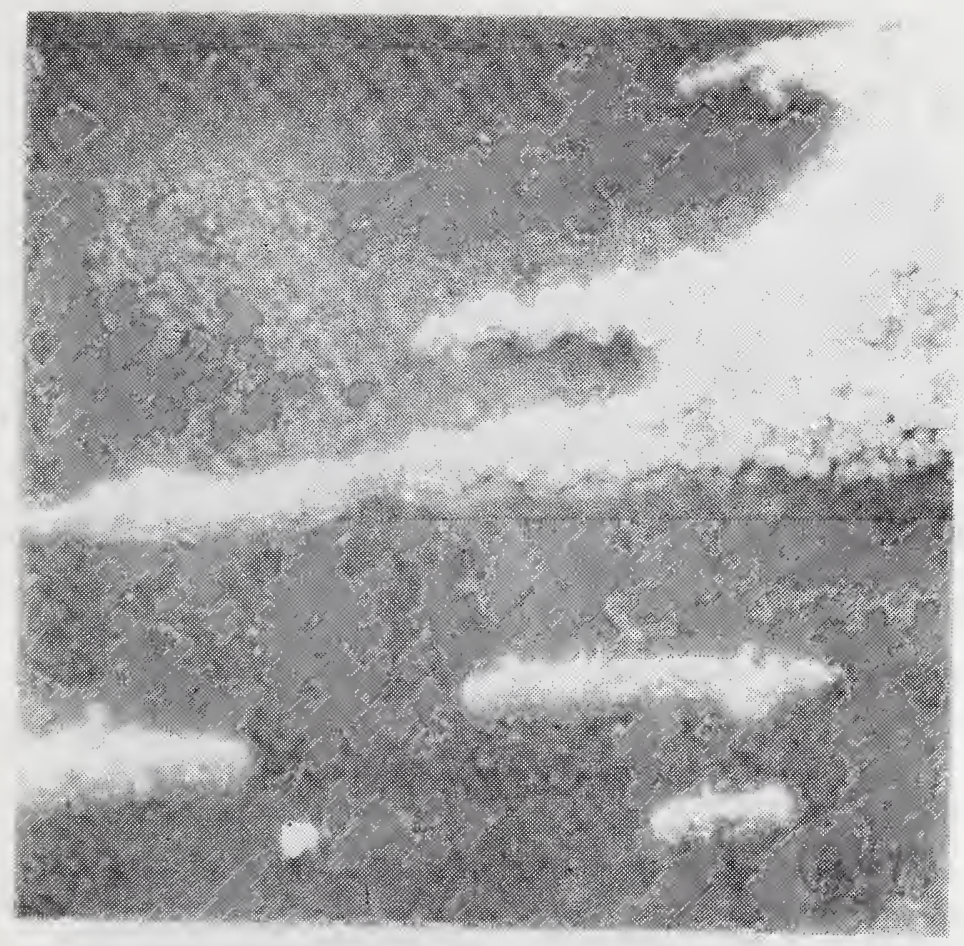

Figure 15

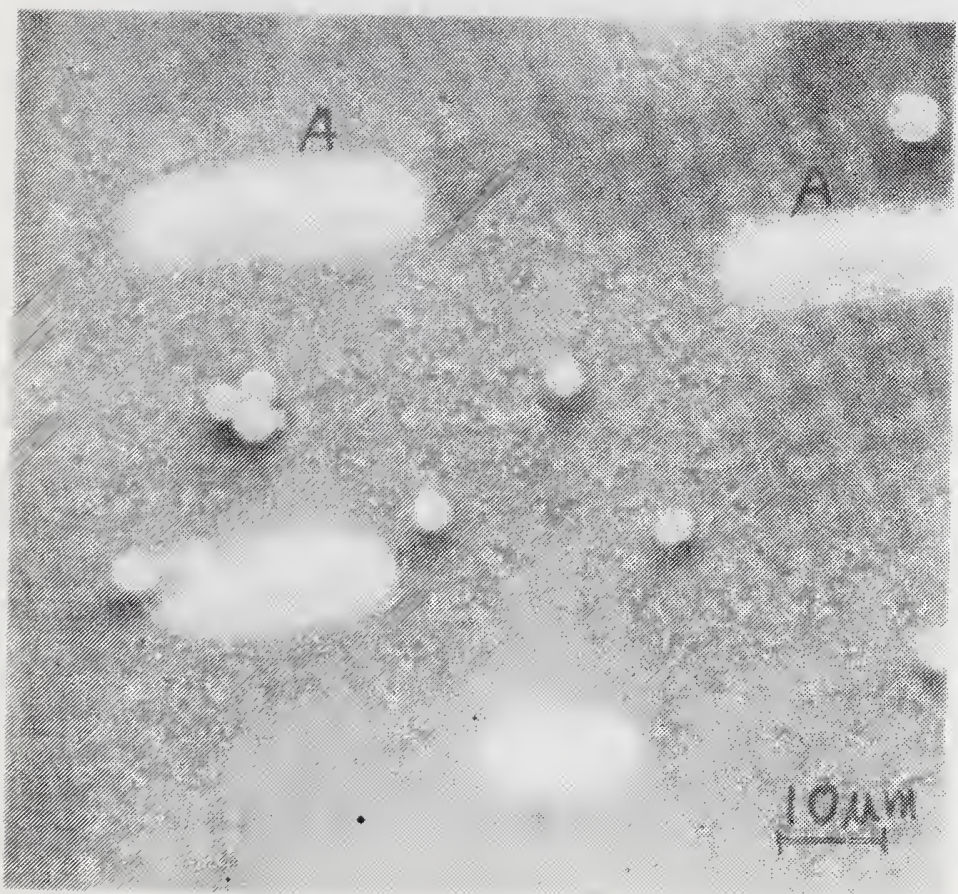

Figure 16 


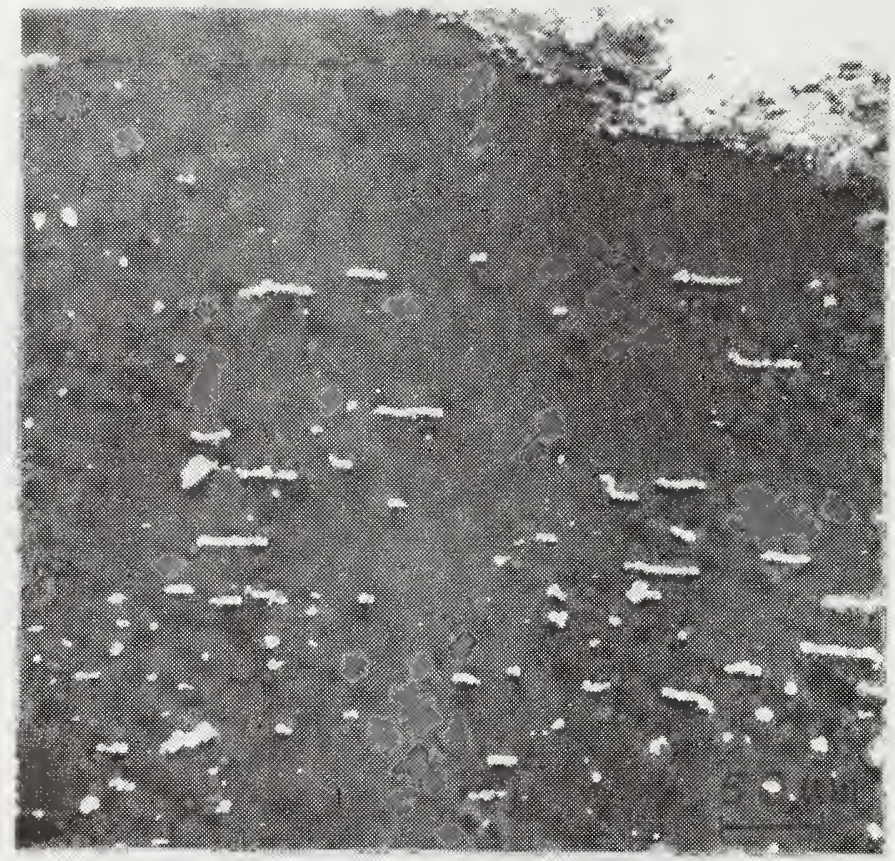

Figure 17

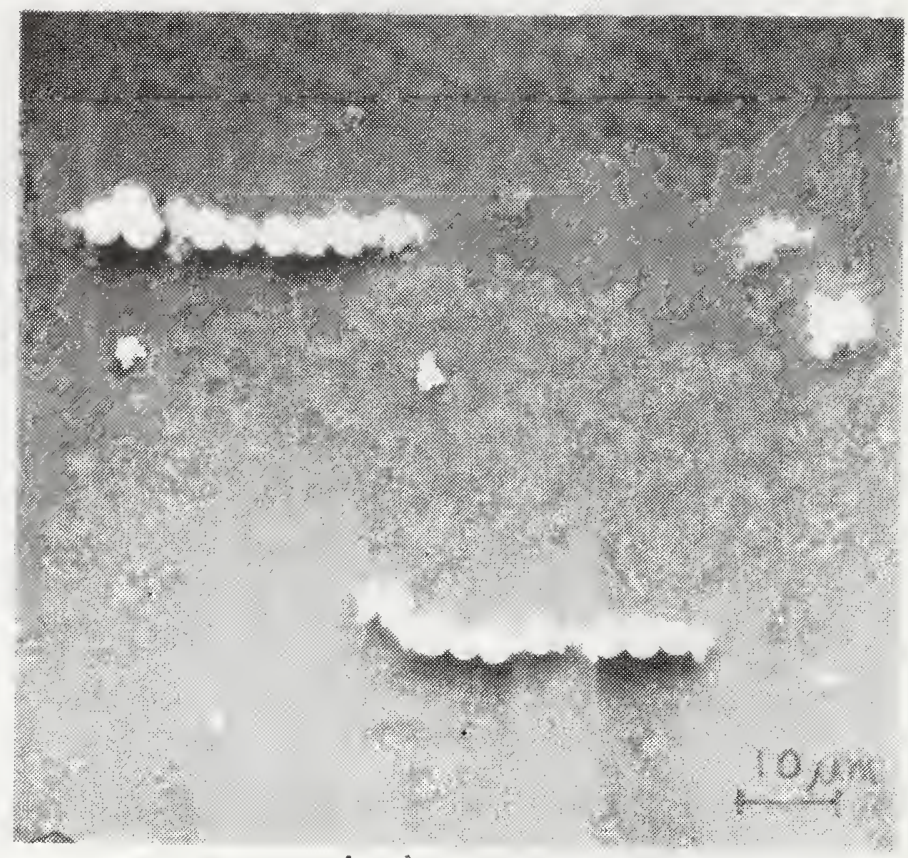

Figure 18 


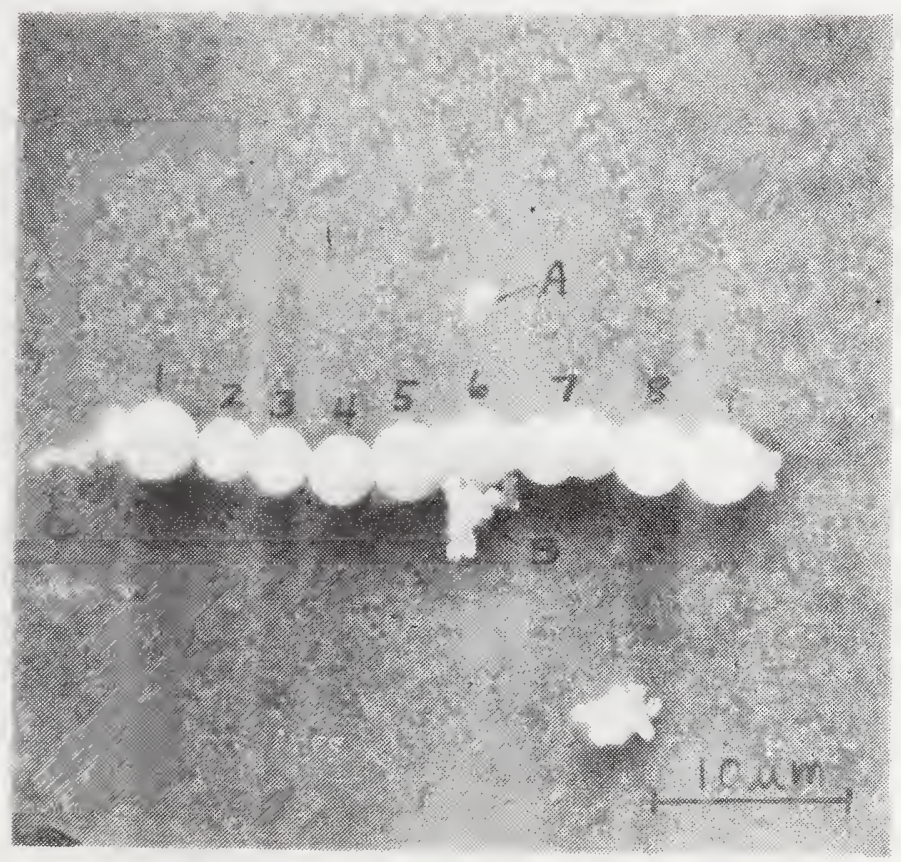

Fiqure 19 


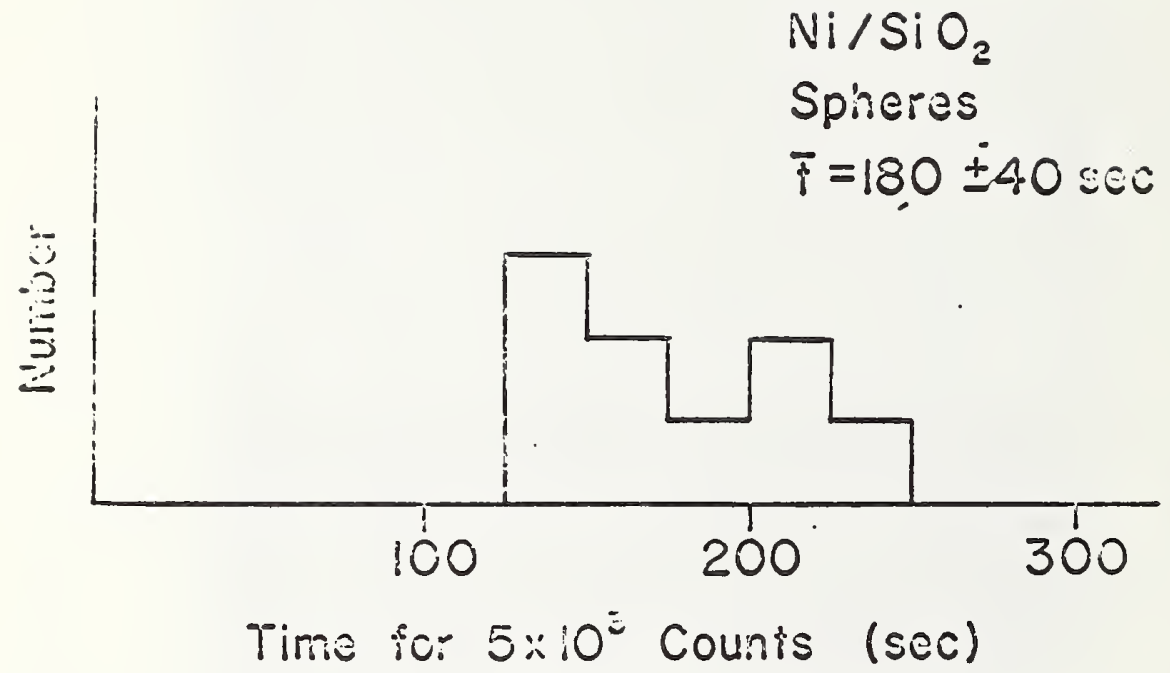

Fiqure 20

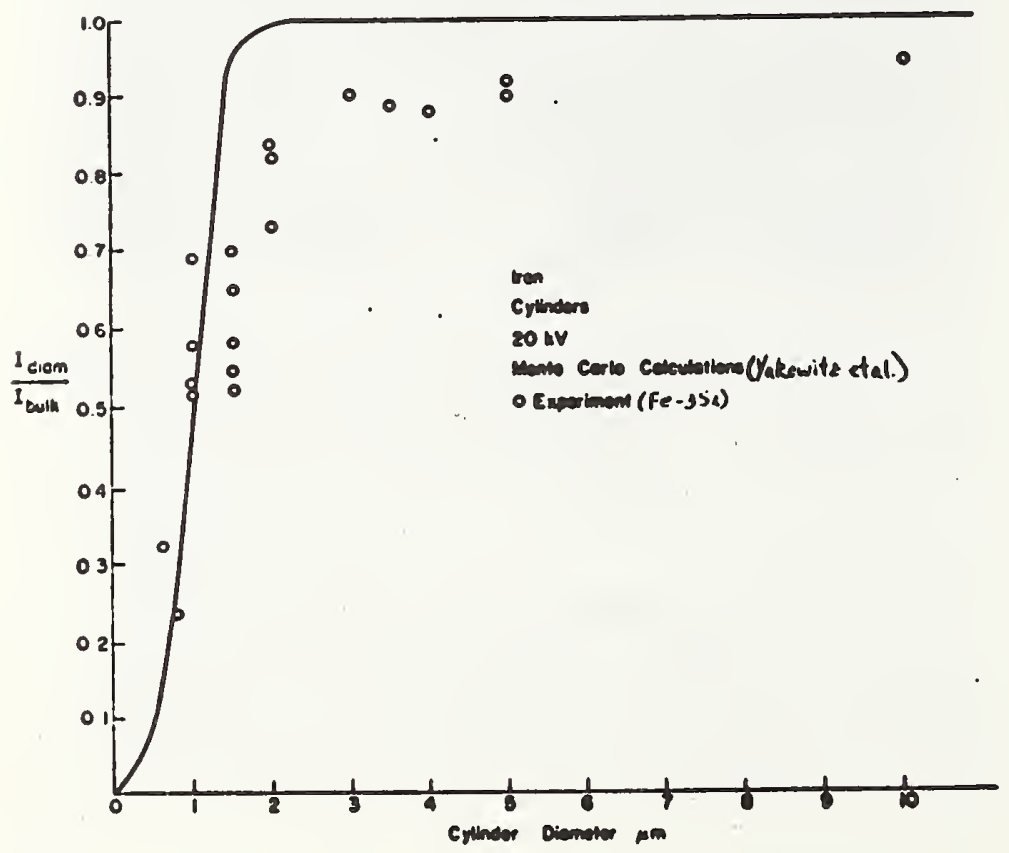

Fiaure 21 
T S. ORT. OF COMM. BIULIOGRAPHIC DATA SHEF.T

4. 1111.1: ANI) SIJ13171.1:
1. IJUII,IC:ATION (HK Klil'OKT NO.

NBSIR 75-640
2. Cinv't Accesnion No.

3. Recipient's Accession No.

5. Publicetion Uatc

Metallurgical Analysis of Wear Particles and Wearing Surfaces

6. Performing Crganization Code

8. Performing Orgnn. Report No.

A. W. Ruff

9. PIERIOORMIN(; ORLIANIZATION NAMII: ANI) AUDHESS

NATIONAL BUREAU OF STANDARDS

DEPARTMENT OF COMMERCE

WASHINGTON, D.C. 20231

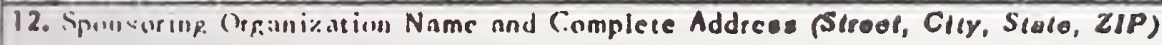

Department of the Navy

ilaval Air Engineering Center

Philadelphia, Pa. 19112

10. l'rojcel/lask/Hork Unit No. 3120437

11. Cosserace/Grane No

4-8049

13. "lype of Report \& l'eriod croverced

Interim Report $10 / 1 / 74=12 / 31 / 24$

14. Sponsoring Arency Code

15. SIIPI.IIMI:NTARY NOTFS

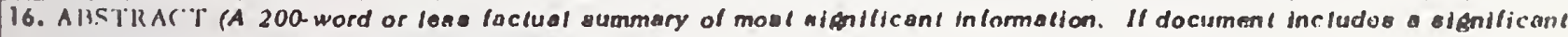
biblinkraphy of literalure aurvey, mantion $\|$ hero.)

The objective of the project has been to characterize the wear particies and surface degradation produced by wear in bearing and gear tests in which the effect of several variables on failure of the wear surfaces has been examined. The inforination obtained has been correlated with the results of allied studies conducted by others in an attempt to develop an understanding of the processes producing wear and degradation of metal surfaces on sliding, rubbing, rolling, and/or rotating contact and the effects of lubricants, lubricant additives, bearing materials, etc. on these processes. The characterization of the wear particles and wearing surfaces should aid in the establishment of the interrelationships between wear particle shape, size, size distribution, chemical compositions, metallurgical structure, and surface damage prior to failure.

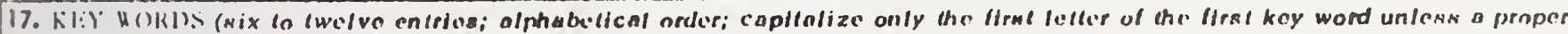

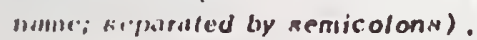

Bearings; debris; electron microscopy; lubrication; metals; particle analysis; wear.

18. AVA11.A1111.1\%Y

[n Unlimital

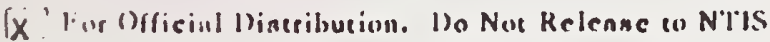

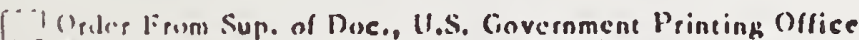
Wuling:ton, D.C.. 20102, Sil C.R. Nu. C.13

[" Ireler lipom National Technical' Information Sctvice (N7IS) Spriugficld, Virginia 22131
19. Slic:IIR\%Y C.I.ASS ('TliIS R kPURT)

UNCI. ASSIJIIT:D

20. Sl:C:UKITY (I.ASS (TIIIS PAGE)

UNCLASSII:IEU
21. NO. OF PAGES

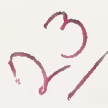

22. Price 
